\title{
Feasibility and preliminary diagnostic results of pixel-wise quantification of regadenoson first pass cardiac magnetic resonance perfusion imaging
}

\author{
Allison D Ta ${ }^{1,2^{*}}$, Li-Yueh Hsu' ${ }^{1}$, Christopher A Miller ${ }^{1}$, Anders M Greve ${ }^{1}$, Hannah Conn', Susanne Winkler ${ }^{1}$, \\ Peter Kellman ${ }^{1}$, Kim-Lien Nguyen ${ }^{1}$, Sujata M Shanbhag ${ }^{1}$, Marcus Y Chen ${ }^{1}$, W Patricia Bandettini ${ }^{1}$, Andrew E Arai ${ }^{1}$
}

From 17th Annual SCMR Scientific Sessions

New Orleans, LA, USA. 16-19 January 2014

\section{Background}

In this study we evaluate the diagnostic accuracy of myocardial perfusion pixel maps for detecting coronary artery disease (CAD). We also compare the performance of perfusion pixel maps with and without myocardial segmentation.

\section{Methods}

Forty-seven patients had $1.5 \mathrm{~T}$ steady state free precession, regadenoson stress perfusion CMR and either a $\leq$ $30 \%$ coronary narrowing by CT angiography (CTA) or a $\geq 70 \%$ stenosis by invasive coronary angiography (ICA). CMR perfusion pixel maps were generated by a modelconstrained deconvolution with and without the myocardial segmentation. The two independent observers were blinded to clinical information.

\section{Results}

Significant coronary stenoses were present in 22 of 47 patients. The diagnostic accuracy of pixel-wise quantification of myocardial perfusion is summarized in Table 1. All of the pixel maps were of diagnostic quality (Figure 1). Interobserver agreement was excellent for ROI guided pixel maps (kappa 0.87). Agreement between readers for perfusion pixel-maps made without ROIs was kappa = 0.59 . One reader tended towards higher sensitivity while the other reader favored specificity.

${ }^{1} \mathrm{NHLBI}$, Bethesda, Maryland, USA

Full list of author information is available at the end of the article

\section{Conclusions}

Fully quantitative stress perfusion analysis at a pixel level has significant potential in clinical settings. As evidence of feasibility, diagnostic quality perfusion pixel

Table 1 Diagnostic Accuracy of Pixel-wise Quantification of Regadenoson Perfusion

\begin{tabular}{ccccccc}
\hline & & Sensitivity & Specificity & Accuracy & PPV & NPV \\
\hline No ROls & Obs 1 & 0.82 & 0.88 & 0.85 & 0.86 & 0.85 \\
\hline & Obs 2 & 0.95 & 0.6 & 0.77 & 0.68 & 0.94 \\
\hline Epi/Endo ROls & Obs 1 & 0.77 & 0.96 & 0.87 & 0.94 & 0.83 \\
\hline & Obs 2 & 0.86 & 0.92 & 0.89 & 0.9 & 0.88 \\
\hline
\end{tabular}

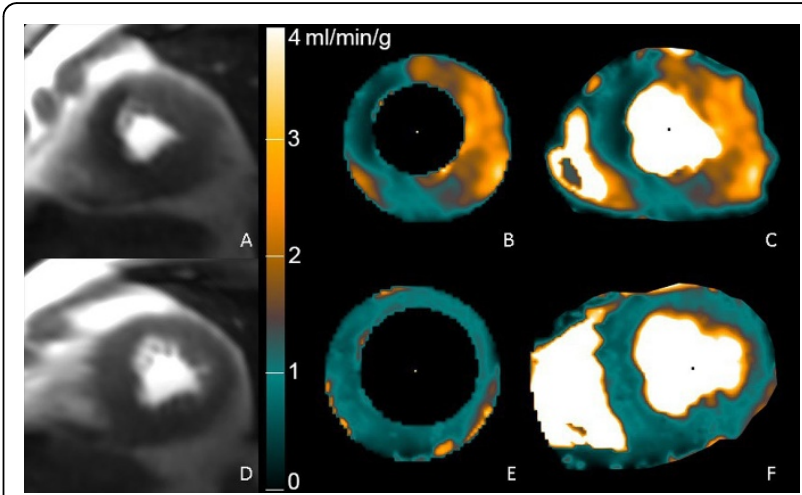

Figure 1 Perfusion Pixel-Maps in a patient with 85\% LAD and RCA stenoses. A) stress perfusion image, B) pixel map generated using Epi/Endo ROls, C) pixel map generated without ROl's. D), E) and $F$ ) are the rest images and perfusion maps. 
maps could be generated without the spatial constraints of the epicardial and endocardial ROIs.

\section{Funding}

ADT is supported by the Sarnoff Cardiovascular Research Foundation. CM is supported by the National Institutes of Health Research, UK. ADT, LH, HC, SW, $\mathrm{KN}, \mathrm{PK}, \mathrm{SS}, \mathrm{MC}, \mathrm{PB}$, and AA are supported by the National Institutes of Health, USA.

\section{Authors' details}

${ }^{1} \mathrm{NHLB}$, Bethesda, Maryland, USA. ${ }^{2}$ Duke University School of Medicine, Durham, Maryland, USA.

Published: 16 January 2014

doi:10.1186/1532-429X-16-S1-P214

Cite this article as: Ta et al:: Feasibility and preliminary diagnostic results of pixel-wise quantification of regadenoson first pass cardiac magnetic resonance perfusion imaging. Journal of Cardiovascular

Magnetic Resonance 2014 16(Suppl 1):P214.

Submit your next manuscript to BioMed Central and take full advantage of:

- Convenient online submission

- Thorough peer review

- No space constraints or color figure charges

- Immediate publication on acceptance

- Inclusion in PubMed, CAS, Scopus and Google Scholar

- Research which is freely available for redistribution

Submit your manuscript at www.biomedcentral.com/submit 